\title{
The Research of Knowledge Management of Virtual Learning Team
}

\author{
Li Cuibai \\ College of Elementary Education \\ Hainan Normal University \\ Haikou, Hainan, China
}

405900956@qq.com

\author{
Liu Fang \\ College of Informational Technology \\ Hainan Normal University \\ Haikou, Hainan, China
}

\begin{abstract}
Virtual team learning is a learning new style in the information era, which is effective measures to improve the efficiency of online learning. Based on the definition of virtual team learning and knowledge management, the thesis expounds the necessity of knowledge management of virtual team learning, and puts forward the creation of local learning team and virtual learning teams together, and induces knowledge management strategy of virtual team learning in the information era. Finally, combining with the reflection of practice, the paper summarizes virtual team learning should pay attention to adopt the strategies of knowledge management of virtual learning team in the information technology environment .
\end{abstract}

Keywords: Virtual learning team; knowledge management; information technology environment; strategy of knowledge management

\section{INTRODUCTION}

Virtual learning teams as virtual learning with local hybrid learning team, is a word combining with learning team, network learning, and virtual learning community. The compound of three concept, is sometimes translated into network learning community. Using method of literature research, case analysis and questionnaire survey, this paper systematically analyze and summarize up the knowledge management theory of virtual learning team, combining with network learning project which Hainan Normal University Students " Cross-school Network communication community" case, summarizes the strategy of knowledge management of virtual learning and skills of the team in the information age, to provide strategies of online learning effective teaching and learning skills.

\section{THE CONCEPT OF VIRTUAL TEAM LEARNING AND KNOWLEDGE MANAGEMENT}

\section{A. Definition of learning team}

Harvard business school professor David a. Gavin thinked that the learning organization is an creating, acquisition and transfer of knowledge organization, also must be good at to modify its behavior at the same time, to increase the new knowledge and insights. Gavin thinked learning organization is to make the organization members and the organization itself widely absorbs the knowledge with scientific method, transfer the structure of knowledge and creating knowledge [1].Learning organization is based on "systems thinking" for the purpose, based on the "team learning", has the vitality of social organization, including enterprise, society and school, etc. [2]."Learning team" is very similar with the concept of "learning organization", team is a kind of organizational form. The difference is that "learning team" generally refers to smaller, the hierarchical structure of the primary organization is simple, such as learning in college courses teaching team, student organizations, class society, inquiry learning team, etc.

\section{B. Connotation of knowledge management}

Knowledge management as a kind of organization management mode under the knowledge economy, has penetrated the innovative companies, education department in knowledge-based organizations, etc. According to the productivity and quality research center (APQC), the definition of Knowledge Management, referred to as KM (Knowledge Management), refers to in order to enhance the competitiveness of enterprises and the recognition of Knowledge, obtain and give full role of the process. Systematic and organizational knowledge management based on knowledge management, improve the organization of collective knowledge capture, development and management, knowledge reengineering and autonomous learning consciousness and level, is to promote knowledge innovation, knowledge sharing, build innovative culture atmosphere, and enhance the core competitiveness of the organization [3].

\section{Virtual learning team and knowledge management}

Virtual learning team is a group of professional knowledge, professional sharing a common passion and common goals, they are not only focused on the construction of individual knowledge, the improving of the individual learning ability, and emphasizes the collaboration communication through the Internet, interaction to form the collective knowledge. In a virtual team learning is the process of operation, proper use of knowledge management concept, methods and techniques, not only improve team members' individual autonomous learning and knowledge utilization level of consciousness, and able to manage resources distribution in the crowd a lot of knowledge, but also improve the organizational performance of the learning team.

Knowledge cycle pay attention to knowledge management includeing knowledge acquisition, sharing, utilization and innovation of the complete process of knowledge management of knowledge in the crowd movement process, the process involves the internalization and externalization, socialization and combination of knowledge. And the operation process of the learning team 
just has the characteristics of knowledge transformation, the process embodies the explicit knowledge and tacit knowledge transformation and creation of [4].Emphasis on the knowledge management of virtual learning teams, it will be conducive to knowledge sharing and transformation of dynamic management, promoting knowledge innovation virtual learning teams.

\section{CASE OF ANALYSIS OF CROSS-SCHOOL LEARNING VIRTUAL TEAMS}

\section{A. The Case of Cross-school Students' Reading Virtual Team}

Cross-school students' Reading Virtual Team is a successful case of virtual learning teams, it is based on the current college students' reading method to change this trend, combining with virtual team learning team into the popular in current college students BBS, QQ group, Blog group elements such as virtual learning teams are formed, the objective is for college students to establish a virtual book exchange platform, at the same time to strengthen the collaborative learning between different schools. Cross-school college students' network reading exchange club, relying on the inquiry learning of the course of Learning Science and Technology, regularly held a large book exchange based on local activities and online evaluation activities. Local researchers have 17 people, serval guide teachers, different personnel involved undergraduate students of other universities of more than 80 people, the main professional of team members include the science of educational technology, education, information technology disciplines.

\section{B. The creation of Cross-school Students' Reading Virtual Team}

Cross-school Students' Reading Virtual Team formed mainly in two stages, the first stage based on local efforts to form a good learning team in reality, the second phase is virtual learning teams which established through the Internet. Self-question in the process of forming processes, promote the integration of local learning team and network virtual learning team, the depth of the fusion of knowledge integration team growth. The whole course of creating of virtual learning teams often from the following process as Fig.1. "Create virtual learning teams and local team together".The virtual team learning form in addition to the benign interaction between the local learning team, mainly relying on the virtual communities, online activities and support platform technology.

\section{THE MANAGEMENT STRATEGY OF VIRTUAL LEARNING TEAM}

Learning team as a new type of learning organization, it has the general community process that include "rise development - mature" the basic development characteristics. As a result, the development of learning team should be around the features and constituent elements of building. The concrete manifestation are 1 operation management of learning team, daily management of learning virtual team, sharing of the information technology environment management, a variety of local activities and the management of the network activity.

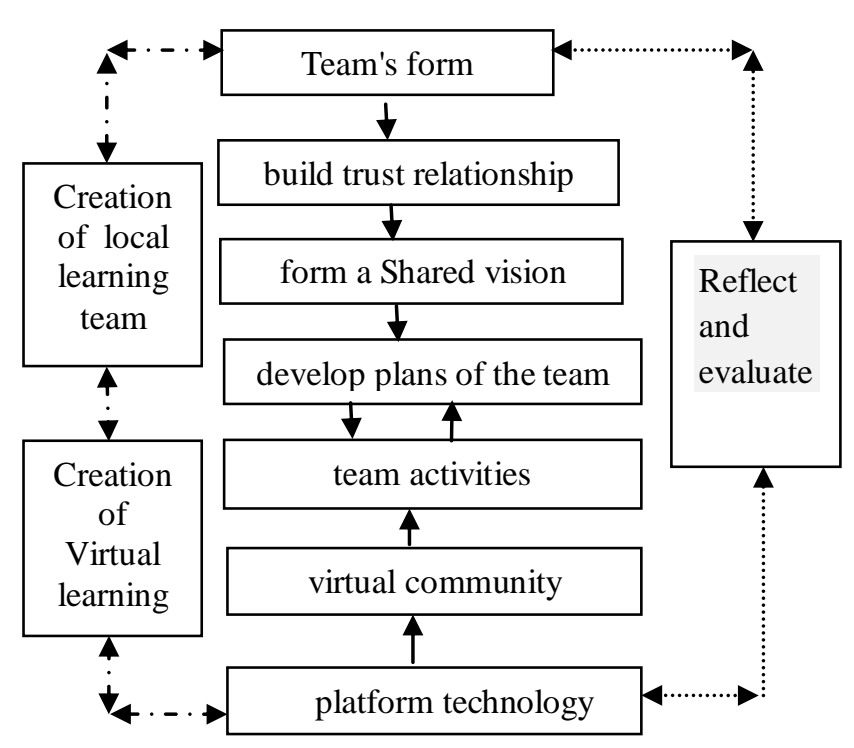

Fig.1. Create virtual learning teams and local team together

\section{A. Operation management of learning virtual team}

Learning is a process of gradual development and operation team. Knowledge management is the management of the whole cycle of knowledge, knowledge acquisition, sharing, utilization and the management of innovation is a complete cycle. In the process of the development of the learning team, with the continuous expansion of community, to improve the learning and team also need to constantly deepening and innovation of knowledge, good knowledge management can promote the ascension of social organizations and individual learning performance [5]. It can be said that the operation process of the learning team management is vital to ensure team fast growth, successful team learning need to constantly in the organization and operation management work with community members suggest that demand and balance between ideas.

\section{B. Daily management of learning virtual team}

Norms Specification is the basic code of conduct of the learning team members in the group, moderate and reasonable team norms is not only beneficial to ensure the team members to participate in the basic requirement of daily activities, avoid to produce passive, neglect or confusion; And help members of the sense of responsibility and moral duty in team affairs, development team regularly participate in activities [5].Generally speaking, the main learning team members through team meeting to reflect, the publication of the book, network learning log to release form such as strict with their daily team activities.

The tacit knowledge of the learning team includes both the knowledge base (such as: team members exchange their experience, team leaders, rich management experience), including explicit knowledge (such as: form text web logs, comments or integrated electronic works and all sorts of study resource).Knowledge management is 
the key to motivate "tacit knowledge" to "explicit knowledge". Necessary specification is not only the basic link of management program, but also help promote team daily to participate in activities, so as to cultivate learning team knowledge management culture of [6]

\section{Sharing information technology instruction and environment}

The formation technology environment of virtual learning team is the basic condition of survival, virtual learning team learning team. Learning virtual team is a group of mutual learning knowledge, Sharing knowledge, using knowledge and innovation of knowledge of people, each learner in the process of team have learned a lot of course information and knowledge resources, personal experience, team learning knowledge, interpersonal interaction, and about the team's study plan, mission planning, and many other materials. The learning of team usually built in QQ group, blog group, project site, BBS, etc. In a variety of Shared information technology of environment, the learners should combine the daily learning and personal knowledge management, writing learning experience, regularly release team learning logs, sorting data such as habit. [7]

\section{Tthe management of local activities and the network activities}

The mature of the learning team, team members grow, effective team learning environment gradually formed, inseparable from a variety of local activities combined with network activity design. Combining local and network activities, not only the successful learners synchronous and asynchronous, real-time and non-realtime communication collaborative learning, also to the formation of personal knowledge in the process of communication and team knowledge and explicit knowledge and tacit knowledge in a variety of local activities and the network transmission, sharing, using and innovation, pushing the whole learning team run smoothly, form the orderly development pace. [8]

\section{CONCLUSIONS}

Virtual learning Team is an effective way of online learning through the development based on the knowledge management of virtual team,.It can effectively enhance the level of knowledge construction of network learners' and improve the ability of learners' using of information tools, cultivating the ability of learners' collaborative learning and the comprehensive practice, improving the students' information literacy. Observing from the instructional experiment and practice, it still exist the following problems need to be overcome and improve: (1)The use of information tools. Based on the inquiry learning of the learning team knowledge management effectively carry out the important condition that Shared information technology environment, in the teaching needs to pay attention to cultivate the students' information literacy and basic ability of information tools to use. [9] (2)Evaluation of reward mechanism. Evaluation is indispensable important link, the network learning in the teaching should be based on different research learning activities to develop the corresponding evaluation and reward system, and constantly promote the effective operation of the entire activity and enhance learners' participation motivation. ( 3 ) Online learning of communication. The information technology environment for learning virtual team is collaboration learning provide a good communication platform, which is an important knowledge management strategy of learning team, is so great significance for improving the efficiency of inquiry learning. [10] (4) The individual differences of learners'. Virtual team learning is a new type of network learning organization, is also a kind of new teaching mode, the different types of students have difference on the degree of adapt to this way of learning, there are big differences between initiative of team learning, instructional and management for the learner's individual should be difference

Relationship because of the time and condition, this study selected class of samples is less, the overall situation, to a certain extent affect the research of these aspects of hope in the future teaching research for further effort.

\section{ACKNOWLEDGMENT}

I would like to express my gratitude to all those who have helped me during the writing of this thesis.

The work of this paper is supported by 2010 Humanities and Social Science Foundation of Ministry of Education of China (Grant No. 10YJC880063) and 2015 Instructional Reform Project of Higher Education Foundation of Hainan Educational Committee (Grant No. Hnjg2015ZD -7).

\section{REFERENCE}

[1]Storage section editor. Introduction to knowledge management $[\mathrm{M}]$, Tsinghua university press, version 1 March 2006, pp. 119-117. [2] Sang Xin-min editor. The science of learning and technology $[\mathrm{M}]$, Beijing: Higher education press, version 1 in September, 2004, p. 235. [3] Eric Tsui, mark compilation. Relating to the personal knowledge management (PKM) of some basic concepts. [4] Etienne Wenger.Richard McDermott waiting. Edge Jing. Practice society - learning organization knowledge management manual $[\mathrm{M}]$, Beijing: Mechanical press. 2003.

[5] Li Cuibai.Network learning community knowledge

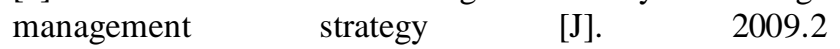
[6] Good news, sun Gao Xianzhong. Virtual community self-organization characteristics and rules of generation problems [J]. Journal of Academic Exchange, 2008 (7) : 143-145.

[7] Wang tao Jiang Chunxiao etc. Concerning the construction of network virtual learning in distance education team $[\mathrm{J}]$. Journal of hebei radio and television university, 2006 [8] Xu Yan.High School Information Technology Course of Research-oriented Learning Design [J]. 2009 
[9] Li Cuibai.Inter-school collaboration network learning community organization strategy _ network curriculum across school collaboration, China audio-visual education $[\mathrm{J}] .2013 .10$
[10]Li Cuibai,“Information technology and curriculum integration, the modern education technology training tutorial,"Beijing:Science $\quad$ Press, 2014.8 